\title{
Detection of M-Protein in Acetonitrile Precipitates of Serum using MALDI-TOF
} Mass Spectrometry

Nikita Mehra $_{a, b}$, Gopal Gopisetty* ${ }_{a}, \mathrm{~S} \mathrm{Jayavelu}_{a}$, Rajamanickam Arivazhagan , Shirley Sundersingh ${ }_{d}$, Parathan Karunakaran ${ }_{b}$, Jayachandran Perumal Kalaiyarasi $_{b}$, Krishnarathinam $\operatorname{Kannan}_{b}$, Venkatraman $\operatorname{Radhakrishnan}_{b}$, Tenali Gnana $\operatorname{Sagar}_{a} \mathrm{~b}$ Thangarajan Rajkumar ${ }_{a}$

${ }_{a}$ Department of Molecular Oncology, Cancer Institute (WIA), Chennai, ${ }_{b}$ Department of Medical Oncology, Cancer Institute (WIA), Chennai, cDepartment of Biochemistry, Cancer Institute (WIA), Chennai, ${ }_{d}$ Department of Onco-pathology, Cancer Institute (WIA), Chennai

*Corresponding author

\section{Abstract}

Purpose of the research

Multiple myeloma and plasmacytomas belong to a group of disorders, namely plasma cell dyscrasias and are identified by the presence of a monoclonal protein (M-protein). MALDITOF-mass spectrometry (MS) has demonstrated superior analytical sensitivity for the detection of M-protein and is now used for screening of M-protein at some centres. We present the results of an alternative methodology for M-protein analysis by MALDI-TOF MS.

\section{Methods}

Serum samples from patients with newly diagnosed multiple myeloma or plasmacytoma with positive M-protein detected by serum protein electrophoresis, immunofixation electrophoresis and serum free light chain analysis, underwent direct reagent-based extraction process using Acetonitrile (ACN) precipitation. Serum $\kappa$ and $\lambda$ light chains were validated using immunoenrichment by anti- $\kappa$ and anti- $\lambda$ biotin-labelled antibodies immobilised on streptavidin magnetic beads. MALDI-TOF MS measurements were obtained for intact proteins using alpha- cyano-4-hydroxycinnamic acid as matrix. The images obtained were overlaid on apparently healthy donor serum samples to confirm the presence of M-protein. 
Principle results:

Characteristic M-protein peaks were observed in the ACN precipitates of serum in the predicted mass ranges for $\kappa$ and $\lambda$. The $\kappa$ and $\lambda$ peaks were confirmed by immunoenrichment analysis. Twenty-seven patient samples with either newly diagnosed multiple myeloma or plasmacytoma with monoclonal gammopathy detected by the standard methods were chosen for Acetonitrile precipitation and analysed by MALDI-TOF MS. All 27 patient samples demonstrated a peak suggestive of M-protein with mass/charge $(\mathrm{m} / \mathrm{z})$ falling within the $\kappa$ and

$41 \lambda$ range. The concordance rate with serum immunofixation electrophoresis and free light

42 chain analysis was above $90 \%$.

Major conclusions:

We report the results of a low-cost reagent-based extraction process using Acetonitrile precipitation to enrich for $\kappa$ and $\lambda$ light chains, which can be used for the screening and qualitative analysis of M-protein.

52 Keywords

53 Multiple myeloma, plasmacytoma, M-protein, acetonitrile, MALDI-TOF, mass spectrometry

\section{Abbreviations}

55 MALDI-TOF- matrix-assisted laser desorption ionization- time of flight

56 MS- mass spectrometry

57 SPEP- serum protein electrophoresis

58 IFE- Immunofixation electrophoresis

59 sFLC- Serum free light chains

60 ACN- Acetonitrile

61 MM- multiple myeloma

$62 \kappa$ - Kappa 
bioRxiv preprint doi: https://doi.org/10.1101/2020.03.13.990192; this version posted March 14, 2020. The copyright holder for this preprint (which was not certified by peer review) is the author/funder. All rights reserved. No reuse allowed without permission.

\section{$63 \lambda$ - Lambda}

$64 \mathrm{~m} / \mathrm{z}$ - Mass to charge ratio

65 
66

67

68

69

70

71

72

73

74

\subsection{Introduction}

Multiple myeloma (MM) and plasmacytoma(s) belong to a group of clonal plasma cell dyscrasias. $(1,2)$ The diagnosis of these disorders is established by the detection of abnormally secreted monoclonal immunoglobulin- M-protein in the blood and sometimes in the urine. Around 2-3\% have truly non-secretory multiple myeloma, i.e., absence of Mprotein. (3)

M-protein is analysed by a multitude of tests, including serum/ urine protein electrophoresis (SPEP/ UPEP), serum/ urine immunofixation (IFE) and serum free light chains (sFLC). The combination of these tests can be laborious, time-consuming and expensive. $(4,5)$

Recent studies have demonstrated the feasibility of employing matrix-assisted laser desorption ionization mass spectrometry- time of flight mass spectrometry (MALDI-TOF MS) for the detection of M-protein in MM and AL amyloidosis termed MASS-FIX. (6-10) MASS-FIX has demonstrated superior analytical sensitivity to IFE and is now used in the clinic. (11) MASS-FIX can be utilised for rapid and accurate estimation of M-protein for screening and diagnosing plasma cell disorders.

The advantage of using MALDI analysis is based on the ability to measure the mass to charge $(\mathrm{m} / \mathrm{z})$ ratios of the light chains: $\kappa \mathrm{m} / z\left([\mathrm{M}+2 \mathrm{H}]^{2+}: 11550-12300 \mathrm{Da},[\mathrm{M}+\mathrm{H}]^{+}: 23100-\right.$ $24600 \mathrm{Da})$, and $\lambda \mathrm{m} / z\left([\mathrm{M}+2 \mathrm{H}]^{2+}: 11100-11500 \mathrm{Da},[\mathrm{M}+\mathrm{H}]^{+}: 22200-23100 \mathrm{Da}\right)$ and high throughput automated analysis. (7) In a healthy individual, secretion of the immunoglobulins by plasma cells in the bone marrow is polyclonal with several plasma cells secreting these proteins. The polyclonal nature of the secretion, upon the analysis in a mass spectrometer, would give rise to a spectrum indicating a Gaussian distribution pattern with no single protein clone ( $\kappa$ or $\lambda$ ) being predominant. (12) However, in the diseased state, due to increased secretion of antibodies by a few clones, there is a distinct secretion pattern which is contrary to the Gaussian distribution pattern and is reflected in MALDI-TOF MS analysis. This distinction in the pattern of protein profile between the healthy and diseased state is diagnostic for monoclonal gammopathy. Another necessary consequence of the analysis of antibody light chains using MALDI-TOF, is that the $m / z$ measurements obtained from the instrument help to determine the nature of the disease which can be categorized as either $\kappa$ or $\lambda$. MASS-FIX is a mass spectrometry-based analysis of M-protein which entails isotypespecific nanobody enrichment along with MALDI-TOF MS. A significant drawback of this procedure is the high cost of the reagents involved. Additionally, the primary reagent 
99 required, namely the $\kappa$ and $\lambda$ specific antibodies, are qualitatively sensitive and prone to

100 show variation during production.

101 Therefore, we felt the need to device a low-cost reagent-based extraction process which can

102 enrich for the $\kappa$ and $\lambda$ proteins and is simultaneously compatible with MALDI-TOF MS.

\subsection{Materials and Methods}

108 Control and patient samples were collected after obtaining Institutional Ethics Committee

109 approval for carrying out a study on biomarker discovery in plasma cell disorders. The work

110 was carried out in accordance with the Declaration of Helsinki after obtaining written

111 informed consent. Excess control serum samples were obtained from healthy blood product

112 donors who provided a sample for preliminary screening. Patients with confirmed plasma cell

113 disorders with monoclonal gammopathy detected by SPEP, serum IFE or FLC, or a

114 combination of these tests were included for MALDI-TOF MS analysis using the extra serum 115 sample.

\subsubsection{SPEP, serum IFE and FLC Analysis}

SPEP was performed on the Minicap/ FP fully automated capillary electrophoresis analyser

120 (Sebia, France) and serum total protein concentration was determined by colorimetric method 121 using biuret reagent on BA400 fully automated clinical chemistry analyser (manufactured by

122 Bio system S.A., Spain) in the Department of Biochemistry. From the total protein value, the 123 software automatically quantified each fraction $(\alpha 1, \alpha 2, \beta 1, \beta 2$ and $\gamma$ globulins). With the

124 help of a pointer on the screen, the M-band area was marked manually, and the instrument 125 automatically calculated the concentration of M-protein from the total protein value.

126 Serum IFE was performed on SAS-3 9IF gel (Helena Biosciences) and reported.

127 sFLC was analysed on BN II Nephelometer by Siemens using the Binding Site kit.

\section{$129 \quad$ 1.2.3 Reagent-based extraction}

130 The serum fraction was separated from whole blood by centrifugation at $5000 \mathrm{rpm}$ for 15 131 minutes and stored at $-80^{\circ} \mathrm{C}$ until further analysis. $25 \mu \mathrm{L}$ of the serum was taken in a fresh $132500 \mu L$ centrifuge tube and mixed with $400 \mu L$ of extraction solution (50\% Acetonitrile 
133 (ACN) prepared in mass spectrometry grade water), the mixture was thoroughly mixed

134 allowing the protein fraction to precipitate. Mass spectrometry grade ACN and LC-MS grade

135 water were both obtained from Sigma-Aldrich. The mixture was incubated at room

136 temperature $\left(28^{\circ} \mathrm{C}\right)$ for 5 minutes. The mixture was centrifuged at 12,000 rpm for 10 minutes,

137 and the protein precipitate was collected. The protein precipitate was washed with wash

138 solution (20\% ACN prepared in mass spectrometry grade water). It was mixed with equal

139 volumes, i.e., $400 \mu \mathrm{L}$ of $20 \% \mathrm{ACN}$ and the precipitate was mixed thoroughly. The solution

140 was centrifuged at 10,000 rpm for 10 minutes. The supernatant was discarded, and the

141 precipitate was retained. After the wash, the wash solution was removed to the maximum

142 extent possible. The precipitate was reconstituted in $200 \mu \mathrm{L}$ reconstitution buffer: $10 \%$ formic

143 acid (FA) and $50 \mathrm{mmol} / \mathrm{L}$ tris(2-carboxyethyl)phosphine hydrochloride (TCEP). The

144 reconstituted solution was centrifuged at $12000 \mathrm{rpm}$ for 10 minutes. TCEP was purchased

145 from Tokyo Chemical Industry Co., LTD and formic acid with 98\% purity purchased from

146 Sigma-Aldrich.

\subsubsection{Antibody Immuno-enrichment}

150 The procedure for immunoenrichment was performed as previously described (7) with some modifications as described. Due to the non-availability of agarose beads and nanobodies targeting $\kappa$ and $\lambda$ constant region domains, our protocol was modified to include direct use of biotin-labelled $\kappa$ and $\lambda$ antibodies and subsequently immobilized in streptavidin magnetic beads. $25 \mu \mathrm{L}$ of serum was diluted in $225 \mu \mathrm{L}$ of LC-MS grade water and added to a mixture of $5 \mu L$ each of $\kappa$ and $\lambda$ antibodies along with $5 \mu L$ of streptavidin beads. Captureselect Biot A-light chain $\kappa \mathrm{HU}$ and light chain $\lambda \mathrm{HU}$ antibodies and Myone Streptavidin T1 beads were purchased from Thermo Fisher Scientific. The diluted serum, along with the antibody-coated bead mixture, were combined and incubated at room temperature for 45 minutes. This mixture was then washed five times with LC-MS grade water and eluted with $40 \mu \mathrm{L}$ elution

160 buffer (10\% FA, $50 \mathrm{mmol} / \mathrm{L}$ TCEP). This was vortexed for 15 minutes.

\subsubsection{MALDI-TOF Analysis}

163

164 One $\mu L$ of the protein solution was spotted along with MALDI matrix (alpha- cyano-4-

165 hydroxycinnamic acid, $10 \mathrm{~g} / \mathrm{L}$ in $50 \%$ Acetonitrile $+0.1 \%$ TFA) onto MALDI ground steel

166 plate and allowed to dry. The samples were then analysed using Ultraflex ${ }^{\mathrm{TM}}$ LT, Bruker

167 MALDI/TOF-TOF mass spectrometer. Mass measurement was analysed with a summation of 
168

169

170

171

172

173

174

175

176

177

178

179

180

181

182

183

184

185

186

187

188

189

190

191

192

193
500-5000 shots depending on the intensity of the M-peak. The mass spectra for each sample was exported to FlexAnalysis 3.3 (Bruker Daltonics) and background subtracted. Before analysis, the MALDI mass spectrometer was calibrated using protein standard (Bruker Daltonics).

\subsubsection{Interpretation of M-protein}

A sample was considered positive for M-protein if there was a sharp or broad peak within the $\kappa$ or $\lambda \mathrm{m} / \mathrm{z}$ mass spectra range. (7) All the patient samples were overlaid on a healthy serum control mass spectra with the polyclonal distribution of $\kappa$ and $\lambda$ light chains.

\subsection{Results}

\subsubsection{Identification of $\kappa$ and $\lambda$ chains in ACN precipitates of serum (Fig. 1a and b)}

The amount of serum sample was tested in the range from $10 \mu L-100 \mu L .25 \mu L$ was chosen for further analysis because, at this loading amount, the intensity of M-peak made the detection unambiguous (data not shown). We tested a range of concentrations for ACN from $10 \%$ to $100 \%$ and found that $50 \%$ was optimal for analysis (data not shown). We spotted a range of sample concentrations on the MALDI plate: neat, 1:10, 1:25, 1:50 and 1:100. Neat and 1:10 concentration were found to be suitable for further analysis. The neat sample was spotted on the MALDI plate for all control and patient samples.

All the images were acquired at a $m / z$ range of 10000-29000 Da to include the $[\mathrm{M}+\mathrm{H}]^{+1}$ and $[\mathrm{M}+2 \mathrm{H}]^{+2}$ charge states for $\kappa$ and $\lambda .[\mathrm{M}+2 \mathrm{H}]^{2+}$ charge state images were chosen for further analysis due to superior visual sensitivity as already described in the MASS-SCREEN analysis. (7)
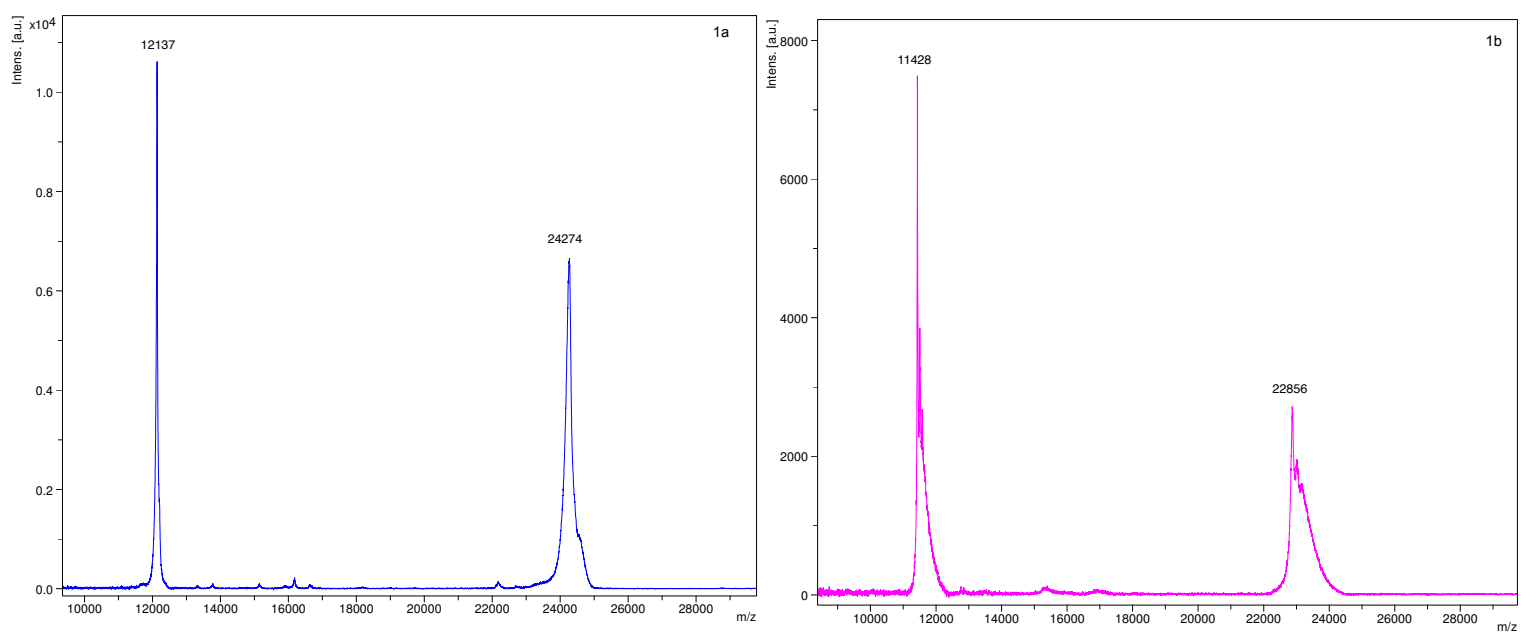
196 Figure 1a: FLC mass spectra with $[\mathrm{M}+\mathrm{H}]^{+}$and $[\mathrm{M}+2 \mathrm{H}]^{+2}$ charge states for a patient serum

197 (sample no.2- Table 1) with $\kappa$ monoclonal gammopathy by Acetonitrile precipitation.

$198[\mathrm{M}+\mathrm{H}]^{+}-24274 \mathrm{Da} \&[\mathrm{M}+2 \mathrm{H}]^{+}-12137 \mathrm{Da}$.

199 Figure 1b: FLC mass spectra with $[\mathrm{M}+\mathrm{H}]^{+}$and $[\mathrm{M}+2 \mathrm{H}]^{+2}$ charge states for a patient serum

200 (sample no: 6) with $\lambda$ monoclonal gammopathy by Acetonitrile precipitation. $[\mathrm{M}+\mathrm{H}]^{+}-$

$20122856 \mathrm{Da} \&[\mathrm{M}+2 \mathrm{H}]^{+}-11428 \mathrm{Da}$.

202 1.3.2 Validation of ACN precipitation results with Immunoenrichment with $\kappa$ (Fig. 2a and b) 203 and $\lambda$ antibodies (Fig. $3 a$ and $b$ )

204

205 Immunoenrichment was performed for two known $\kappa$ M-protein samples and, two $\lambda$ M-

206 protein samples. The mass spectra were found to be identical with the light chain $\mathrm{m} / \mathrm{z}$ falling

207 within the range as reported by immunoenrichment.
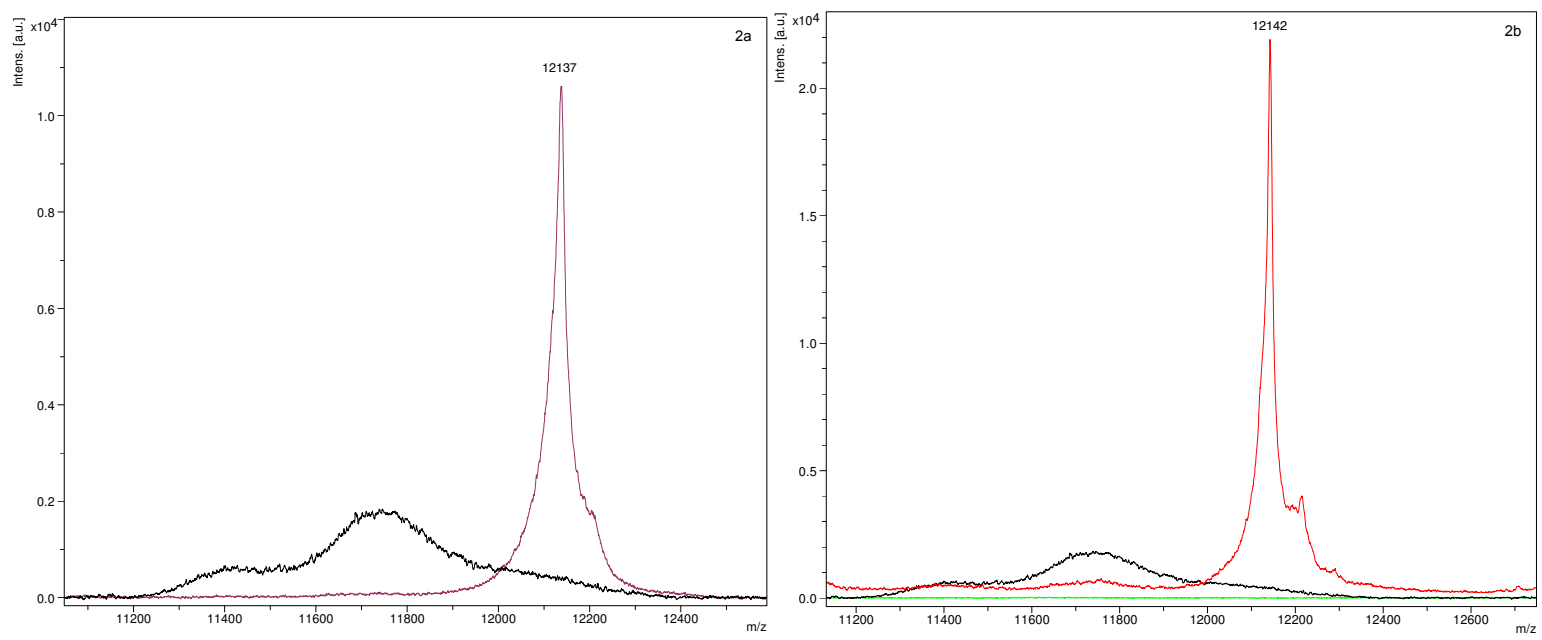

210 Figure 2: Patients serum (sample no. 2- Table 1) sample with $\kappa$ monoclonal gammopathy

211 Figure 2a: FLC mass spectra showing a sharp M-peak (violet) overlaid on a healthy serum

212 control (black) by Acetonitrile precipitation.

213 Figure $2 \mathrm{~b}$ : Immunoenrichment with $\kappa$ antibody tagged to streptavidin beads from the same

214 patient showing a sharp M-peak (red) overlaid over a healthy serum control (black) and

215 streptavidin bead control with no peak (green). 

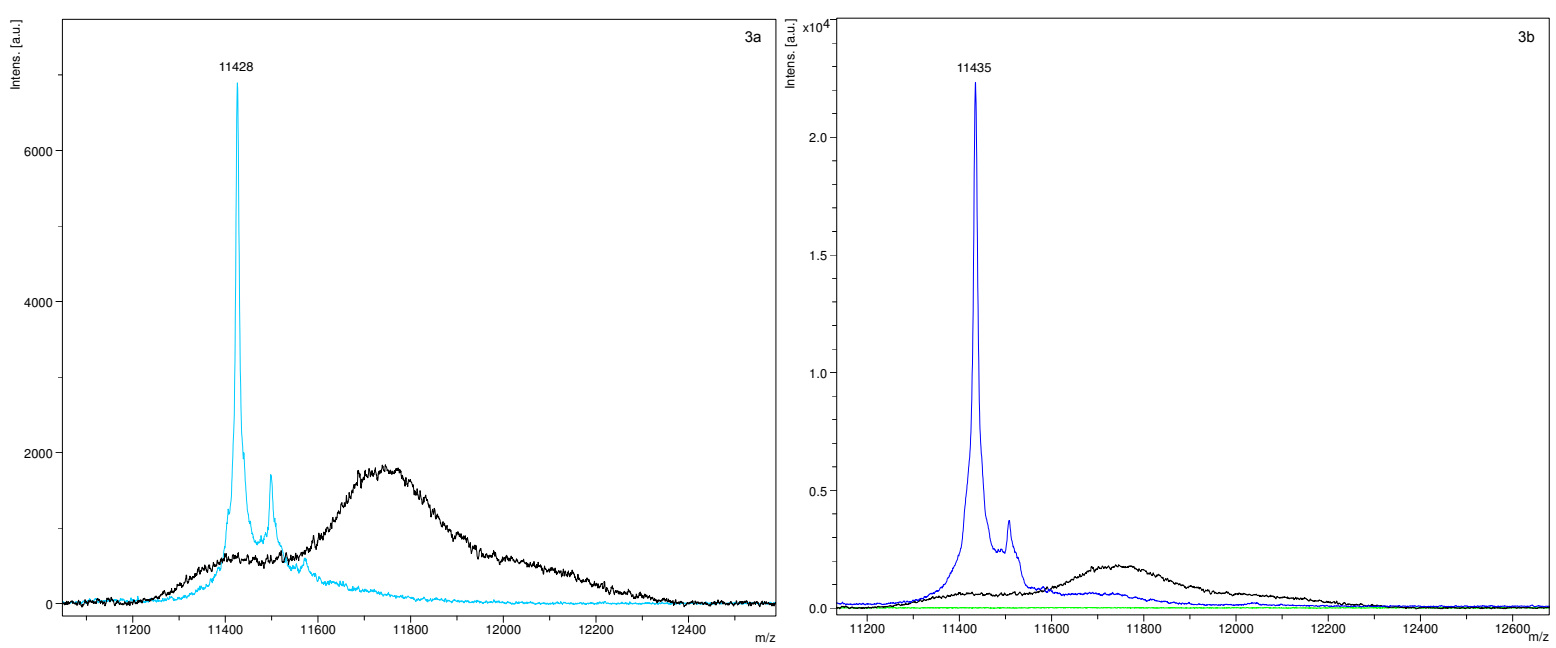

219 Figure 3: Patient's serum (sample no. 6- Table 1) with $\lambda$ monoclonal gammopathy

220 Figure 3a: FLC mass spectra showing a sharp M-peak (blue) overlaid on a healthy serum 221 control (black) by Acetonitrile precipitation.

222 Figure 3b: Immunoenrichment with $\lambda$ antibody tagged to streptavidin beads from the same

223 patient showing a sharp M-peak (blue) overlaid over a healthy serum control (black) and

224 streptavidin bead control with no peak (green).

225 1.3.3 ACN precipitation of the control serum samples (Fig. 4)

The Gaussian distribution of light chains was obtained by analysing 20 control samples from extra serum samples of apparently healthy blood donors. All the control samples underwent SPEP. Serum protein concentration for all samples was within normal limits, and SPEP did not demonstrate M-protein. 


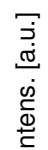

Figure 4: Mass spectra at $[\mathrm{M}+2 \mathrm{H}]^{2+}$ charge state of all the healthy serum controls

235 demonstrating the Gaussian distribution of polyclonal $\kappa \& \lambda$ light chains.

\subsubsection{Patient samples}

Twenty-four patients were newly diagnosed with multiple myeloma and, three with solitary plasmacytoma. The baseline characteristics of these patients are shown in Table 1.

241 A mass spectrometrist S.J was blinded to the IFE and FLC results- blinded analyst. N.M was the unblinded analyst. All the 27 samples with monoclonal gammopathy confirmed by the other biochemical techniques, demonstrated a positive M-peak on MALDI-TOF MS (100\%). 


\begin{tabular}{|c|c|c|c|c|c|c|c|c|c|c|c|}
\hline \multirow{2}{*}{$\begin{array}{l}\text { Sample } \\
\text { No }\end{array}$} & \multirow{2}{*}{$\begin{array}{l}\text { Age } \\
\text { and } \\
\text { Sex }\end{array}$} & \multirow[t]{2}{*}{ Diagnosis } & \multirow{2}{*}{$\begin{array}{l}\text { ISS }^{l} \\
\text { Stage } \\
\text { (for } \\
\text { MM) }\end{array}$} & \multirow{2}{*}{$\begin{array}{c}\mathrm{LDH}^{2} \\
\text { in } \\
(\mathrm{U} / \mathrm{L})\end{array}$} & \multirow{2}{*}{$\begin{array}{c}\text { SPEP: } \\
\text { M- } \\
\text { protein } \\
\text { conc. } \\
(\mathrm{g} / \mathrm{dL}) \\
\end{array}$} & \multirow{2}{*}{$\begin{array}{l}\text { Serum } \\
\mathrm{IFE}^{3}\end{array}$} & \multicolumn{3}{|c|}{ Serum free light chain ${ }^{4}$} & \multirow[b]{2}{*}{$\begin{array}{l}\text { M-peak (+2 charge } \\
\text { state in Da) }\end{array}$} & \multirow[b]{2}{*}{ MAL-TOF MS Analysis } \\
\hline & & & & & & & $\begin{array}{l}\text { Kappa } \\
(\mathrm{mg} / \mathrm{L})\end{array}$ & $\begin{array}{l}\text { Lambda } \\
(\mathrm{mg} / \mathrm{L})\end{array}$ & Ratio & & \\
\hline 1. & $67 / F$ & MM & III & 393 & 4 & $\mathrm{IgG} \kappa$ & 75.5 & 27.5 & 2.745 & 11689 & $\kappa$ \\
\hline 2. & $50 / \mathrm{F}$ & MM & II & 421 & 3.3 & $\mathrm{IgG} \kappa$ & 655 & 5.87 & 111.584 & 12137 & $\kappa$ \\
\hline 3. & $63 / \mathrm{F}$ & Plasmacytoma & $\mathrm{N} / \mathrm{A}^{5}$ & N/A & 0.8 & $\mathrm{IgG} \kappa$ & $\mathrm{N} / \mathrm{D}$ & $\mathrm{N} / \mathrm{D}$ & $\mathrm{N} / \mathrm{D}$ & 11725 & $\kappa$ \\
\hline 4. & $44 / \mathrm{M}$ & $\mathrm{MM}$ & $\mathrm{I}$ & 286 & 2.3 & $\operatorname{IgG} \lambda$ & 1.25 & 245 & 0.005 & 11489 & $\lambda$ \\
\hline 5. & $52 / \mathrm{M}$ & MM & II & Missed & 3.2 & $\mathrm{IgG} \kappa$ & 16.7 & 2.95 & 5.661 & 11869 & $\kappa$ \\
\hline 6. & $69 / \mathrm{F}$ & MM & III & 474 & 8.8 & $\operatorname{IgG} \lambda$ & 14.5 & 798 & 0.018 & 11428 & $\lambda$ \\
\hline 7. & $57 / \mathrm{F}$ & $\mathrm{MM}$ & II & 466 & 3.8 & $\mathrm{IgG} \kappa$ & 374 & 9 & 41.556 & 11681 & $\kappa$ \\
\hline 8. & $63 / \mathrm{F}$ & MM & III & 206 & 4 & $\operatorname{IgA} \kappa$ & 32.5 & 2.55 & 12.75 & 11678 & $\kappa$ \\
\hline 9. & $67 / \mathrm{M}$ & MM & II & 336 & 3 & $\mathrm{IgG} \kappa$ & 571 & 9.54 & 59.853 & 11708 & $\kappa$ \\
\hline 10. & $68 / \mathrm{F}$ & MM & III & 319 & Absent & $\lambda$ & 34.6 & 2550 & 0.014 & 11488 & $\lambda$ \\
\hline 11. & $52 / \mathrm{M}$ & MM & III & 1022 & 4.9 & $\mathrm{~N} / \mathrm{D}^{6}$ & N/D & $\mathrm{N} / \mathrm{D}$ & N/D & 11720 & $\kappa$ \\
\hline 12. & $59 / \mathrm{M}$ & $\mathrm{MM}$ & II & 280 & 5 & $\mathrm{~N} / \mathrm{D}$ & 37.9 & 2.01 & 18.856 & 11636 & $\kappa$ \\
\hline 13. & $54 / \mathrm{F}$ & Plasmacytoma & N/A & N/A & 1.2 & $\mathrm{~N} / \mathrm{D}$ & $\mathrm{N} / \mathrm{D}$ & $\mathrm{N} / \mathrm{D}$ & $\mathrm{N} / \mathrm{D}$ & 11751 & $\kappa$ \\
\hline 14. & $58 / \mathrm{M}$ & $\mathrm{MM}$ & III & 260 & 4.7 & $\mathrm{IgG} \kappa$ & N/D & $\mathrm{N} / \mathrm{D}$ & $\mathrm{N} / \mathrm{D}$ & 11692 & $\kappa$ \\
\hline 15. & $47 / \mathrm{M}$ & MM & II & 260 & 2.8 & $\operatorname{IgA} \kappa$ & 90.1 & $<0.05$ & $\begin{array}{c}\text { Not } \\
\text { calculable } \\
\end{array}$ & 11558 & $\kappa$ \\
\hline 16. & $48 / \mathrm{F}$ & $\mathrm{MM}$ & II & 445 & Absent & $\kappa$ & 6070 & 3.3 & 1839 & 11797 & $\kappa$ \\
\hline 17. & $64 / \mathrm{M}$ & $\mathrm{MM}$ & N/A & N/A & Absent & Normal & 1433 & 13.79 & 103 & 11796 & $\kappa$ \\
\hline 18. & $59 / \mathrm{F}$ & Plasmacytoma & N/A & N/A & Absent & $\mathrm{N} / \mathrm{D}$ & 51 & 16 & 3.188 & 11818 & $\kappa$ \\
\hline 19. & $46 / \mathrm{F}$ & $\mathrm{MM}$ & II & 830 & 2.2 & $\operatorname{IgG} \lambda$ & 1.17 & 1530 & 0.001 & 11377 & $\kappa$ \\
\hline 20. & $44 / \mathrm{M}$ & MM & $\mathrm{I}$ & 415 & 1.2 & $\operatorname{IgG} \lambda$ & 16.9 & 16.2 & 1.043 & 11649 & $\kappa$ \\
\hline 21. & $62 / \mathrm{F}$ & MM & III & 596 & 1.9 & $\operatorname{IgA} \kappa$ & 3710 & 9.06 & 409.492 & 11835 & $\kappa$ \\
\hline 22. & $72 / \mathrm{F}$ & $\mathrm{MM}$ & II & 283 & 2.2 & $\mathrm{IgG} \kappa$ & 2740 & 9.31 & 294.307 & 11692 & $\kappa$ \\
\hline 23. & $63 / \mathrm{M}$ & $\mathrm{MM}$ & III & 1657 & 2.7 & $\operatorname{IgA} \kappa$ & 1460 & 10.2 & 143.14 & 12128 & $\kappa$ \\
\hline 24. & $70 / \mathrm{M}$ & $\mathrm{MM}$ & $\mathrm{I}$ & 330 & Absent & $\kappa$ & 3980 & 12.2 & 326.23 & 11729 & $\kappa$ \\
\hline 25. & $64 / \mathrm{M}$ & $\mathrm{MM}$ & II & 379 & 2.3 & $\mathrm{~N} / \mathrm{D}$ & 61.3 & 18.7 & 3.278 & 11706 & $\kappa$ \\
\hline 26. & $64 / \mathrm{F}$ & MM & II & 200 & 4.2 & $\mathrm{IgG} \kappa$ & 70.3 & 3.27 & 21.5 & 11772 & $\kappa$ \\
\hline 27. & $63 / \mathrm{F}$ & $\mathrm{MM}$ & II & 340 & 2.8 & $\mathrm{IgG} \kappa$ & 3750 & 8.39 & 446 & 11580 & $\kappa$ \\
\hline
\end{tabular}

$250{ }^{l}$ ISS- International staging system for multiple myeloma: I-serum $\beta 2$ microglobulin $<3.5 \mathrm{mg} / \mathrm{L}$ and serum albumin $\geq 3.5 \mathrm{~g} / \mathrm{dL}$; II- Not stage

251 I or III; III- serum $\beta 2$ microglobulin $\geq 5.5 \mathrm{mg} / \mathrm{L}$

$252{ }^{2}$ LDH normal range: 200-400 U/L (serum LDH is a prognostic marker in the R-ISS staging system)

$253{ }^{3}$ IFE was reported at Dr LalPath labs (IgD and IgE immunotyping was not performed)

$254{ }^{4}$ Serum free light chain was reported at SRL Diagnostics

$255 \quad{ }^{5}$ N/A- Not applicable

$256 \quad{ }^{6} \mathrm{~N} / \mathrm{D}-$ Not done (missing)

Table 1: Baseline characteristics of patients and comparison of monoclonal gammopathy

259 results by SPEP, serum IFE, sFLC and Acetonitrile precipitation by MALDI-TOF MS

263 Three samples were labelled as confounders due to low peak intensity in the $\kappa$ mass spectra.

264 However, their peaks matched the sFLC results as reported on serum IFE and sFLC. 

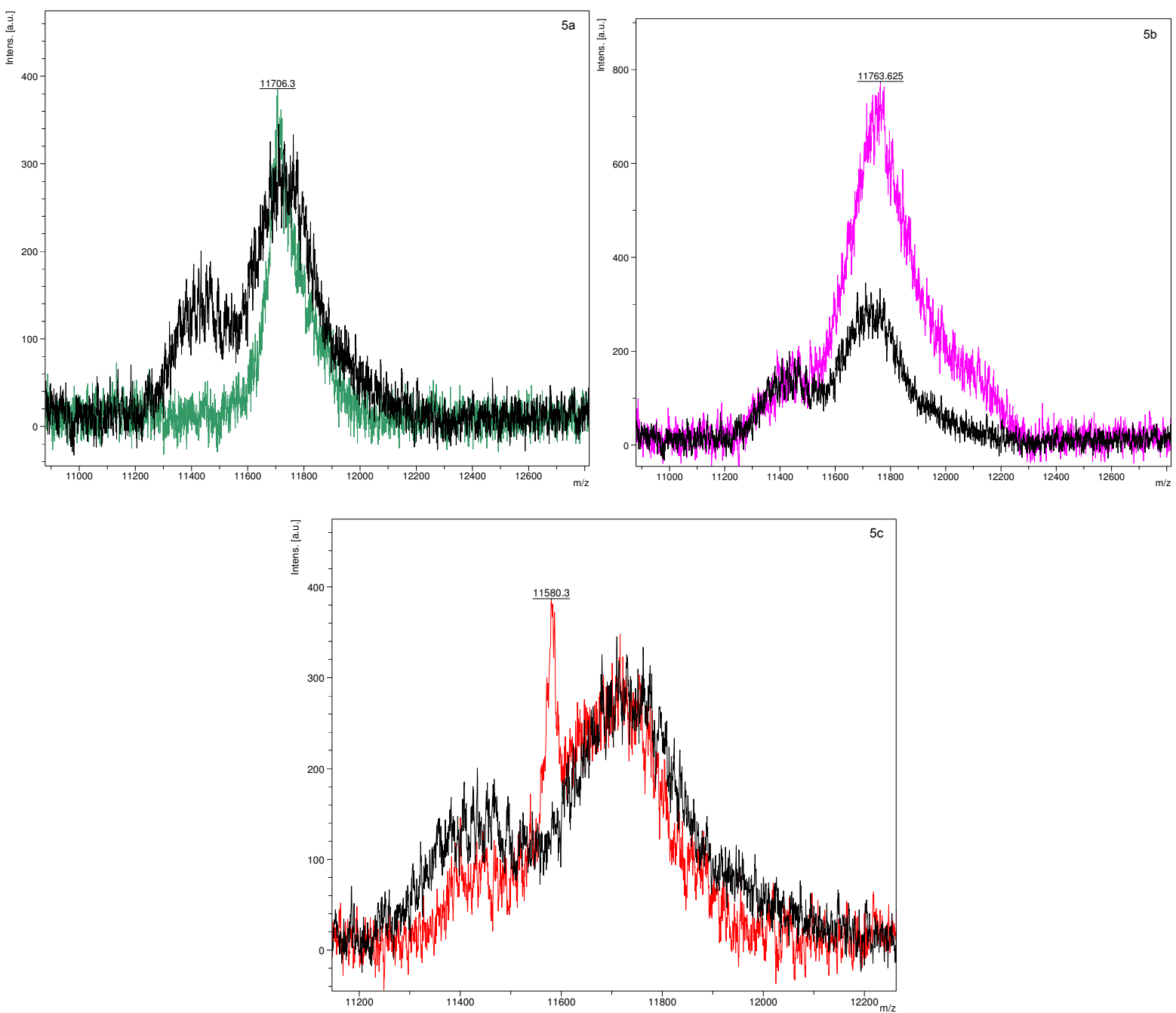

268 Figure 5: Mass spectra of the confounding samples- 5a and b: Serum (sample no. 25 and 26, respectively- Table 1) from two different patients with $\kappa$ monoclonal gammopathy showing

270 low intensity (green and violet, respectively) in comparison with a healthy serum control

271 (black). Note: The $m / z$ of the peak in these patient's samples falls within the $\kappa \mathrm{m} / \mathrm{z}$ range.

272 5c: Mass spectra of serum (sample no. 27- Table 1) from a patient with $\kappa$ monoclonal 273 gammopathy confirmed by serum IFE and sFLC analysis showing a low-intensity $\kappa$ peak 274 (red) overlaid on a healthy serum control (black).

278 Serum IFE and sFLC analysis were sent to independent laboratories for external validation of the MALDI-TOF MS results. 
Among all the 27 patients with positive M-protein on MALDI-TOF MS, 23 patients had serum IFE results available. Of the 23 patients, IFE and MALDI-TOF MS reports were concordant in 21 patients $(91 \%)$.

283 One patient (sample no: 20- Table 1) had $\operatorname{IgG} \lambda$ reported by serum IFE and sFLC was within normal limits. MALDI-TOF MS demonstrated a clear $\kappa$ M-protein. Immunoenrichment was done which confirmed $\kappa \mathrm{m} / \mathrm{z}$ M-protein. Another patient (sample no: 17- Table 1), had very high $\kappa$ levels reported on sFLC: $\kappa-1433 \mathrm{mg} / \mathrm{L} ; \lambda-13.79 ; \kappa: \lambda$ ratio-103. However, serum IFE was reported normal (repeated twice in two different labs). This patient's MALDI-TOF MS revealed a $\kappa$ M-peak. Therefore, the accuracy in determining the FLC by IFE versus MALDI-TOF MS was 91\%. Accuracy can be given for patient sample no: 20 (Table 1), but here the sFLC was within normal limits, indicating that MALDI-TOF MS was correct in $21 / 21$.

\subsubsection{Concordance with sFLC}

Among all the 27 patients with positive M-protein on MALDI-TOF MS, 24 patients underwent sFLC testing. Of the 24 patients, 23 patients (96\%) had concordant results on MALDI-TOF and sFLC demonstrating an altered $\kappa / \lambda$ ratio $(>1.65$ for $\kappa$ or $<0.26$ for $\lambda)$. One patient had a normal sFLC report- $\kappa-19.9 \mathrm{mg} / \mathrm{L} ; \lambda-16.2 \mathrm{mg} / \mathrm{L}$; ratio- 1.043 . IFE, MALDITOF MS and immunoenrichment confirmed $\kappa$ M-protein on this patient sample. Therefore, the false-negativity rate of FLC determination by nephelometry analysis of sFLC was $4 \%$.

\subsection{Discussion}

302

This study demonstrates the feasibility of qualitatively identifying M-protein without the need for nanobody immunoenrichment using agarose or sepharose beads. (12). M-peak was accurately identified in $100 \%$ of patient serum samples by ACN precipitation using MALDI-TOF MS; in three samples there were low-intensity $\kappa$ peaks which correlated with the free light chain detected on serum IFE and sFLC.

308 This technique demonstrates proof of principle of identifying monoclonal and polyclonal $\kappa$ and $\lambda$ as an alternative methodology for the demonstration of $m / z$ mass spectra by MALDI-

310 TOF MS. The results of this can be further verified by immunoenrichment.

311 The results of this study establish the ability to identify the FLC pattern correctly by ACN

312 precipitation using MALDI-TOF MS in all patient serum samples. MALDI-TOF MS 
313 performed better than the other biochemical assays in the qualitative determination of FLC

314 M-protein.

315 The drawbacks of this study include the small sample size. However, our results confirm the

316 findings published previously regarding the superior analytical sensitivity of M-protein

317 analysis by MALDI-TOF MS. (6-8) There is a need to analyse further the low M-peak

318 intensity identified in the confounding samples which have not been addressed in the present

319 study. The ACN precipitation technique was a qualitative analysis of M-protein as defined by

320 its light chain clone. Further studies will focus on developing a methodology for the analysis

321 of immunoglobulin isoforms and quantitative determination of M-protein using this

322 methodology, as already reported with nanobody enrichment- MASS-FIX. (6) This

323 methodology can also be utilised for the estimation of M-protein in the urine.

324 The ACN precipitation methodology, a low-cost technique could be utilised for its cost-

325 effectiveness in planning an epidemiological study in MGUS in a geographically-defined

326 population in a low and middle-income country like India. This technique can also serve as a

327 useful screening technique for M-protein in a haematology lab. MALDI-TOF MS has also

328 shown an advantage of its use in minimal residual disease (MRD) assessment when

329 compared to bone marrow-based MRD analysis by flow cytometry. (13)

\subsection{Conclusions}

We have developed a low-cost reagent-based extraction process using Acetonitrile precipitation to enrich for $\kappa$ and $\lambda$, for the screening and qualitative analysis of M-protein.

\subsection{Acknowledgements}

We acknowledge the Institute's blood bank staff for helping in the collection of control serum samples for the study, the residents of the Department of Medical Oncology and the Biochemistry staff for coordinating the collection of patient samples.

\subsection{Disclosure of Conflicts of Interest}

Gopal Gopisetty, Nikita Mehra, Subramani Jayavelu, Indian provisional patent application no: 202041009443 
bioRxiv preprint doi: https://doi.org/10.1101/2020.03.13.990192; this version posted March 14, 2020. The copyright holder for this preprint (which was not certified by peer review) is the author/funder. All rights reserved. No reuse allowed without permission.

345

$346 \quad 1.8$ Funding

347

348 This work was supported by the Cancer Institute (WIA) funds. No grant number is

349 applicable.

350 


\section{References}

1. Rajkumar SV. Multiple myeloma: 2016 update on diagnosis, risk-stratification, and management. Am J Hematol. 2016;91(7):719-34.

2. Pham A, Mahindra A. Solitary Plasmacytoma: a Review of Diagnosis and Management. Curr Hematol Malig Rep. 2019;14(2):63-9.

3. Kyle RA, Gertz MA, Witzig TE, Lust JA, Lacy MQ, Dispenzieri A, et al. Review of 1027 Patients With Newly Diagnosed Multiple Myeloma. Mayo Clinic Proceedings. 2003 Jan;78(1):21-33.

4. Rajkumar SV, Dimopoulos MA, Palumbo A, Blade J, Merlini G, Mateos M-V, et al. International Myeloma Working Group updated criteria for the diagnosis of multiple myeloma. The Lancet Oncology. 2014 Nov 1;15(12):e538-48.

5. Rajkumar SV. Updated Diagnostic Criteria and Staging System for Multiple Myeloma. American Society of Clinical Oncology Educational Book [Internet]. 2018 Oct 29 [cited 2020 Mar 2]; Available from: https://ascopubs.org/doi/pdf/10.1200/EDBK_159009

6. Mills JR, Kohlhagen MC, Dasari S, Vanderboom PM, Kyle RA, Katzmann JA, et al. Comprehensive Assessment of M-Proteins Using Nanobody Enrichment Coupled to MALDI-TOF Mass Spectrometry. Clin Chem. 2016;62(10):1334-44.

7. Kohlhagen MC, Barnidge DR, Mills JR, Stoner J, Gurtner KM, Liptac AM, et al. Screening Method for M-Proteins in Serum Using Nanobody Enrichment Coupled to MALDI-TOF Mass Spectrometry. Clinical Chemistry. 2016 Oct 1;62(10):1345-52.

8. Sepiashvili L, Kohlhagen MC, Snyder MR, Willrich MAV, Mills JR, Dispenzieri A, et al. Direct Detection of Monoclonal Free Light Chains in Serum by Use of Immunoenrichment-Coupled MALDI-TOF Mass Spectrometry. Clinical Chemistry. 2019 Aug 1;65(8):1015-22.

9. Murray D, Kumar SK, Kyle RA, Dispenzieri A, Dasari S, Larson DR, et al. Detection and prevalence of monoclonal gammopathy of undetermined significance: a study utilizing mass spectrometry-based monoclonal immunoglobulin rapid accurate mass measurement. Blood Cancer J. 2019 Dec 13;9(12):1-7.

10. Sharpley F, Manwani R, Mahmood S, Sachchithanantham S, Lachmann H, Gillmore J, et al. A Novel Mass Spectrometry Method to Identify the Serum Monoclonal Light Chain Component and Infer Organ Involvement in Systemic Light Chain Amyloidosis. Blood. 2018 Nov 29;132(Supplement 1):4445-4445.

11. Milani P, Murray DL, Barnidge DR, Kohlhagen MC, Mills JR, Merlini G, et al. The utility of MASS-FIX to detect and monitor monoclonal proteins in the clinic. American Journal of Hematology. 2017;92(8):772-9.

12. Barnidge DR, Dasari S, Botz CM, Murray DH, Snyder MR, Katzmann JA, et al. Using Mass Spectrometry to Monitor Monoclonal Immunoglobulins in Patients with a Monoclonal Gammopathy. J Proteome Res. 2014 Mar 7;13(3):1419-27. 
13. Eveillard M, Rustad E, Roshal M, Zhang Y, Ciardiello A, Korde N, et al. Comparison of MALDI-TOF mass spectrometry analysis of peripheral blood and bone marrow-based flow cytometry for tracking measurable residual disease in patients with multiple myeloma. Br J Haematol. 2020 Feb 5 